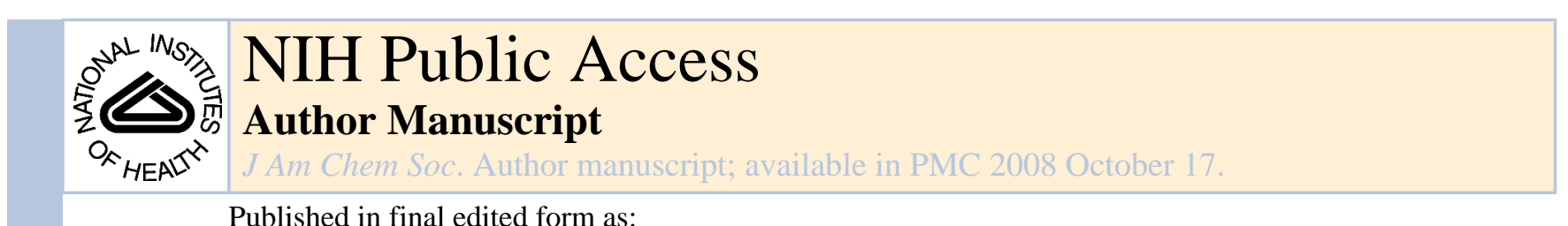

Published in final edited form as:

J Am Chem Soc. 2006 August 23; 128(33): 10664-10665. doi:10.1021/ja062560p.

\title{
Gold-Catalyzed Intramolecular Allylation of Silyl Alkynes Induced by Silane Alcoholysis
}

\author{
Sangho Park and Daesung Lee* \\ Department of Chemistry, University of Wisconsin, Madison, WI 53706
}

\section{Abstract}<smiles>[R]C#C[Si]([R])([R])CC=C[R]</smiles>

The activation of alkynyl allyl silanes with cationic gold catalyst in the presence of alcohols provides a vinyl silanes that contain the allyl group at the $\beta$-position and the alkoxysilyl group in cisorientation. The bond reorganization processe is most consistent with the involvement of a carbocationic intermediate, which undergoes a nucleophilic attack by an alcohol selectively at the silicon center. The cis vinyl silyl ether products can be further elaborated by ring-closing and cross metathesis to form more substituted 1,4-dienyl silanes.

The pursuit of synthetic efficiency has promoted constant development of new concepts and innovated synthetic arsenals. ${ }^{1}$ One of the most effective ways of achieving synthetic efficiency is to implement tandem reactions ${ }^{2}$ into a synthetic sequence whereby many bond-forming and cleaving events can occur in one synthetic operation. Following from our interest in silyl etherbased metathesis chemistry, ${ }^{3}$ we envisioned a tandem reaction to form $\mathrm{C}-\mathrm{H}, \mathrm{C}-\mathrm{C}$, and $\mathrm{Si}-\mathrm{O}$ bonds in one step to generate alkenyl and alkynyl silyl ethers of stereochemically defined vinyl silanes (Eq 1). ${ }^{4}$ Overall, this is a net addition of H-OR to the alkynyl allyl silanes accompanied by an allyl transfer from silicon to carbon. ${ }^{5}$ To achieve this tandem bond formation efficiently, we propose to use carbophilic metal catalysts instead of strong mineral acid catalysts to promote the allyl transfer and the addition of $\mathrm{H}-\mathrm{OR}$ to carbon and silicon centers. Herein we report a stereoselective intramolecular allylation of silyl alkynes to generate alkoxy vinyl silanes via a gold-catalyzed alcoholysis of alkynyl allyl silanes. ${ }^{6}$
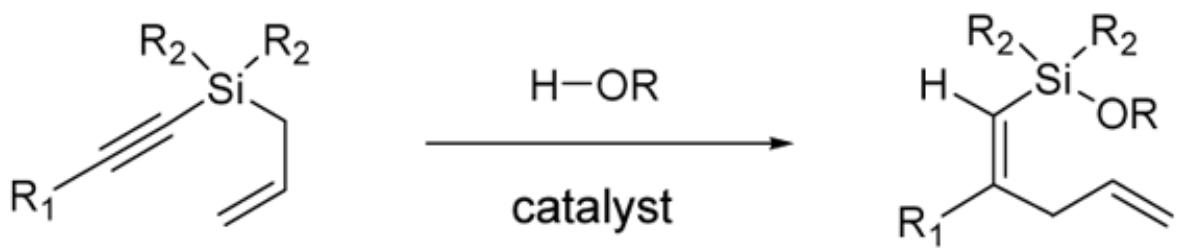

dlee@chem.wisc.edu.

Supporting Information Available: General experimental procedures and characterization of all new compounds. This material is available free of charge via the internet at http://pubs.acs.org 
The general reactivity feature of allyl alkynyl silanes was examined with 1-octynyl allyl dimethylsilane 1a by using several metal catalysts under different conditions (Table 1). ${ }^{8}$ The reaction of $1 \mathrm{a}$ with $\mathrm{Ph}_{3} \mathrm{PAuCl} / \mathrm{AgSbF}_{6}$ in dry $\mathrm{CH}_{2} \mathrm{Cl}_{2}$ at room temperature provided a trace amount of $\mathbf{2 a}$ and $\mathbf{3}$ (entry 1 ). ${ }^{7}$ However, under otherwise identical conditions in undistilled $\mathrm{CH}_{2} \mathrm{Cl}_{2}$, desilylated product 3 was obtained in $93 \%$ yield with small amount of $\mathbf{2 a}$ (entry 2 ). Reaction with $\mathrm{Ph}_{3} \mathrm{PAuCl} / \mathrm{AgOTf}$ gave no conversion (entry 3) whereas $\mathrm{PtCl}_{2}$ (toluene, $90{ }^{\circ} \mathrm{C}$ ) gave product $\mathbf{2 a}$ and $\mathbf{3}$ in $20 \%$ yield (entry 5 ). ${ }^{9}$ The extent of desilylation was reduced by replacing the dimethyl silyl with diphenyl silyl group in $\mathbf{1 b}$, which however, was recovered unchanged (entry 6) under the conditions $\left(\mathrm{Ph}_{3} \mathrm{PAuCl} / \mathrm{AgSbF}_{6}\right.$ in undistilled $\left.\mathrm{CH}_{2} \mathrm{Cl}_{2}\right)$ where 1a gave high conversion. On the other hand, the same reaction with added ${ }^{i} \mathrm{PrOH}$ (1 equiv) provided silyl ether $\mathbf{2 b}$ in good yield (75\%) (entry 7). This clearly indicates that the nucleophilic assistance is crucial for an efficient transfer of allyl group.

Having established optimized conditions for an intramolecular allyl transfer assisted by oxygen-based nucleophiles, we next examined the scope of this reaction by employing allyl silane $1 \mathbf{c}$ and a variety of alcohols (Table 2). Treatment of $\mathbf{1 c}$ with $\mathrm{Ph}_{3} \mathrm{PAuCl} / \mathrm{AgSbF}_{6}$ in dry $\mathrm{CH}_{2} \mathrm{Cl}_{2}$ with $1^{\circ}, 2^{\circ}$, and $3^{\circ}$ alcohols gave good yield of products $4 \mathbf{a}-\mathbf{i}$ as inseparable mixtures of $Z / E$ - isomers in the range of 1:1.7 to 10:1 ratio. A salient feature of these reactions is that the alkene and alkyne functionalities in the alcohol counterpart do not interfere with the reaction.

To broaden the substrate scope, substituents on the alkyne and allyl moieties were introduced (Table 3). ${ }^{8}$ Reaction of $\mathbf{1 b}$ with 4-penten-2-ol under the optimized conditions gave $\mathbf{5}$ in $71 \%$ yield with a 10:1 Z/E ratio (entry 1). Substrate 1d with terminal alkyne provided $\mathbf{6}$ in $85 \%$ yield, however, the stereochemistry of the double bond was scrambled, giving 1:1.7 mixture of $Z / E$ - isomers (entry 2). This is, probably, the consequence of isomerization of the initially formed Z-isomer catalyzed by either the gold catalyst or a proton. ${ }^{10}$ Substrates 1e-g with methyl, phenyl, and benzyloxymethyl substituent on the alkyne behave uneventfully, giving 7-10 in good yields and $Z / E$-selectivity (entries $3-6$ ). On the other hand, substrate $\mathbf{1 h}$ generated more 12 than the expected product $11(81 \%, \mathbf{1 2 : 1 1}=3: 1)$. Presumably, this is the consequence of more favorable activation of the allyl group by the gold catalyst due to the presence of sterically hindered $t$-butyl group on the alkyne. Substrates with alkyl substituent on the allyl segment showed variable reactivity depending on the position of the substituent compared to that of the parent system. ${ }^{11}$ Thus, $\mathbf{1 i}$ bearing a crotyl group gave excellent yields and Z/Eselectivity of $\mathbf{1 3}$ and $\mathbf{1 4}$ (entries 8 and 9), whereas the reaction of methallyl-bearing substrate $\mathbf{1 j}$ provided 1:5.5 mixture of $\mathbf{1 5}$ and the methallyl-displaced product $\mathbf{1 6}$ in $89 \%$ overall yield (entry 10).

From a mechanistic standpoint, we surmised that the activation of the alkynyl moiety of $\mathbf{1}$ by a carbophilic catalyst would induce 6 -endo mode attack ${ }^{12}$ over that of 5-exo by the pendant allyl silyl moiety to generate intermediate $\mathbf{1 7}$ due to the $\beta$-silyl effect on the alkyne moiety (Scheme 1). In the subsequent step, carbocation 17 would undergo a nucleophilic attack at the silicon center by an alcohol to give the final product 4-11and 13-15 after protonolysis of the $\mathrm{C}-\mathrm{Au}$ bond. Despite the sterically hindered environment around the silicon center, presumably, the formation of a strong $\mathrm{Si}-\mathrm{O}$ bond is the driving force to form the observed products.

Although the formation of a putative carbenoid $\mathbf{1 8}$ followed by its alcoholysis is conceivable, products $\mathbf{1 9}$ or $\mathbf{2 0}$ were not observed. ${ }^{13}$ A direct alcoholysis of the allyl moiety of $\mathbf{1}$ was observed when the allyl becomes a methallyl group, which is the consequence of preferential activation of the more electron rich methallyl group over the alkyne by the catalyst, thereby giving product 21.

The utility of this tandem bond-forming technology was further expanded by the ring-closing metathesis ${ }^{14}$ of alkoxy hydroallylation products (Scheme 2). Silyl ethers $\mathbf{4 c}$ and $\mathbf{4 f} / \mathbf{4 g}$ could 
be cyclized by Grubbs complex 2215 to form 10- and 8-membered siloxanes $23-25$ in good yields. Also, the cross metathesis 16 of $4 \mathbf{i}$ with 4-penten-1-ol provided the cross metathesis product $\mathbf{2 6}$ in $42 \%$ yield as a mixture of $Z / E$ isomers.

In conclusion, we have developed a gold-catalyzed tandem intramolecular allyl transfer reactions induced by an alcoholysis of alkynyl allyl silanes, which generate alkoxy vinyl silanes ${ }^{17}$ in high yield and Z/E-selectivity. Synthetic application of this tandem bond-forming process will be reported in due course.

\section{Supplementary Material}

Refer to Web version on PubMed Central for supplementary material.

\section{Acknowledgment}

We thank NIH (RO1 CA106673) and the Sloan Foundation for financial support of this work as well as the NSF and NIH for NMR and Mass Spectrometry instrumentation.

\section{References}

1. Atom-economy: (a) Trost BM. Science 1991;254:1471. [PubMed: 1962206]. Step-economy: (b) Wender PA, Bi FC, Gamber GG, Gosselin F, Hubbard RD, Scanio MJC, Sun R, Williams TJ, Zhang L. Pure Appl. Chem 2002;74:25.

2. Ho, T-L. Tandem organic reactions. Wiley; New York: 1992. (b) Tietze LF. Chem. Rev 1996;96:115. [PubMed: 11848746]

3. (a) Miller RL, Maifeld SV, Lee D. Org. Lett 2004;6:2773. [PubMed: 15281766] (b) Park S, Kim M, Lee D. J. Am. Chem. Soc 2005;127:9410. [PubMed: 15984868]

4. For an intermolecular allyl silylation: Yoshikawa E, Gevorgyan V, Asao N, Yamamoto Y. J. Am. Chem. Soc 1997;119:6781.

5. Silane alcoholysis during enyne cyclization: Fernández-Rivas C, Méndez M, Echavarren AM. J. Am. Chem. Soc 2005;127:12468. [PubMed: 16144376]

6. Alcoholysis of C-Si bond to form silyl ethers: (a) Grimm JB, Lee D. J. Org. Chem 2004;69:8967. [PubMed: 15575786] Acid catalyzed alcoholysis of allylsilane: (b) Morita T, Okamoto Y, Sakurai H. Tetrahedron Lett 1980;21:835.

7. Gold catalyzed alkyne activation, see recent reviews: (a) Ma S, Yu S, Gu Z. Angew. Chem., Int. Ed 2006;45:200. (b) Hashimi ASK. Angew. Chem., Int. Ed 2005;44:6990. (c) Höffmann-Röder A, Krause N. Org. Biomol. Chem 2005;3:387. [PubMed: 15678171] (d) Hashimi ASK. Gold Bull 2004;37:51. (e) Dyker G. Angew. Chem., Int. Ed 2000;39:4237.

8. For the preparation of alkynyl allyl silanes, see Supporting Information

9. Selected examples of most recent $\mathrm{PtCl}_{2}$-catalyzed reaction of enynes: Fürstner A, Davies PW, Gress T. J. Am. Chem. Soc 2005;127:8244. [PubMed: 15941232] and references therein.

10. Another possibility of the scrambling is based on the ipso protonation followed by demetallation of the vinyl metal species.

11. The relative reactivity of allyl and substituted allyl groups in Lewis acid-catalyzed allyl silylation, see Ref 4.

12. A theoretical study for a 6-endo preference for 1,6-enyne possessing a terminal alkyne, see: Soriano E, Ballesteros P, Marco-Contelles J. Organometallics 2005;24:3182.

13. Reactions with all carbon-based system following 18 to 19 and 20, see: Nieto-Oberhuber C, Paz Munoz M, López S, Jiménez-Núnez E, Nevado C, Herrero-Gómez E, Raducan M, Echavarren AM. Chem. Eur. J 2006;12:1677. and references therein.

14. Reviews: (a) Grubbs RH, Chang S. Tetrahedron 1998;54:4413. (b) Fürstner A. Angew. Chem., Int. Ed 2000;39:3012. (c) Schrock RR, Hoveyda AH. Angew. Chem., Int. Ed 2003;42:4592. (d) GrubbsRHHandbook of Metathesis20032Wiley-VCHWeinheim

15. Scholl M, Ding S, Lee CW, Grubbs RH. Org. Lett 1999;1:953. [PubMed: 10823227] 
16. For a review, see: Connon SJ, Blechert S. Angew. Chem., Int. Ed 2003;42:1900.

17. The use of alkoxy vinyl silanes in $\mathrm{C}-\mathrm{C}$ bond formation, see: Denmark SE, Sweis RF. Acc. Chem. Res 2002;35:835. [PubMed: 12379136] 


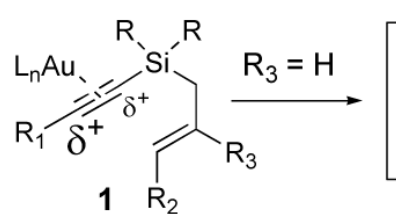

<smiles>CC(C)C</smiles>

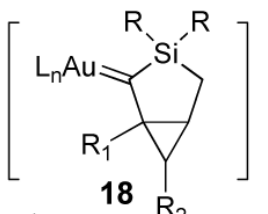

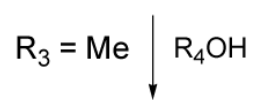



21

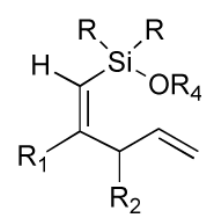

4-11, 13-15



19

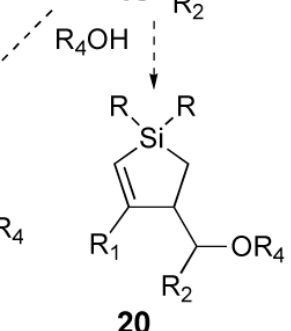

20

Scheme 1.

Gold-Catalyzed Reorganization of Alkynyl Allyl Silane 

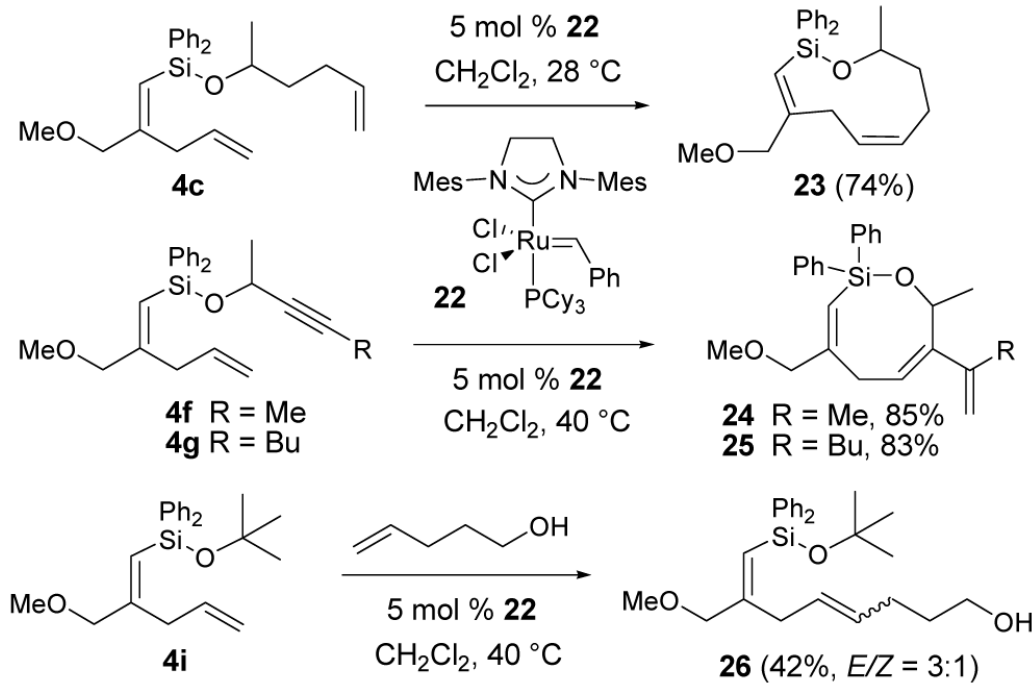

Scheme 2.

Ring-Closing and Cross Metathesis of Silyl Ethers 


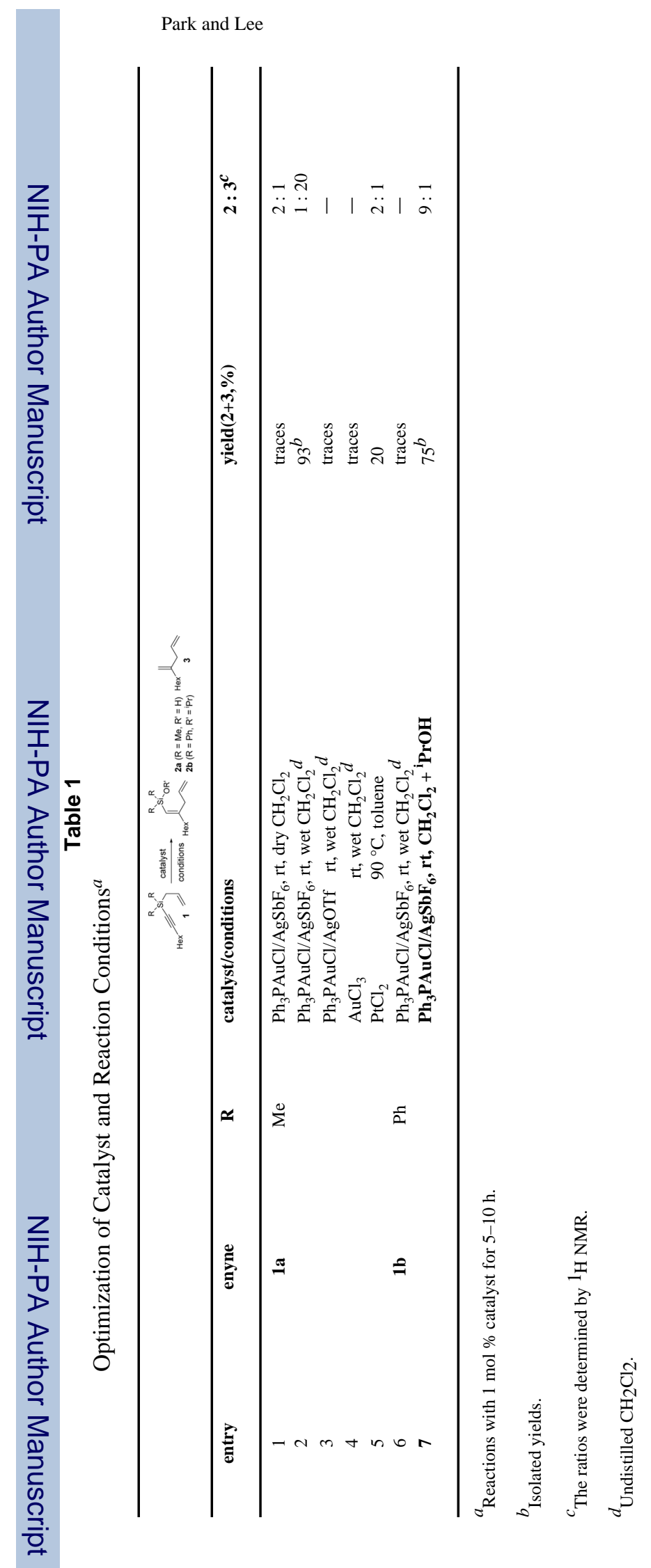

J Am Chem Soc. Author manuscript; available in PMC 2008 October 17. 
Table 2

Intramolecular Allylation-Alcoholysis Catalyzed by Gold ${ }^{a, b}$
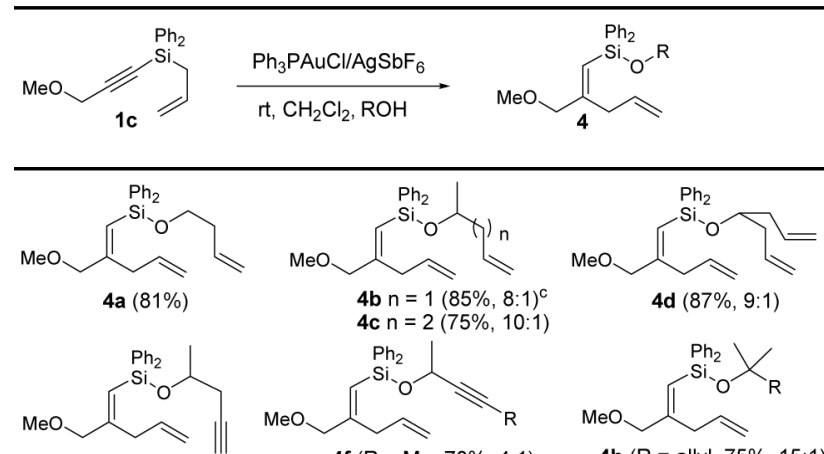

4 e $(86 \%, 8: 1)$


${ }^{a}$ Reactions with $1 \mathrm{~mol} \%$ catalyst for $10 \mathrm{~min}$.

$b_{\text {Isolated yields. }}$

${ }^{c}$ The ratios of major:minor were determined by ${ }^{1} \mathrm{H}$ NMR. 


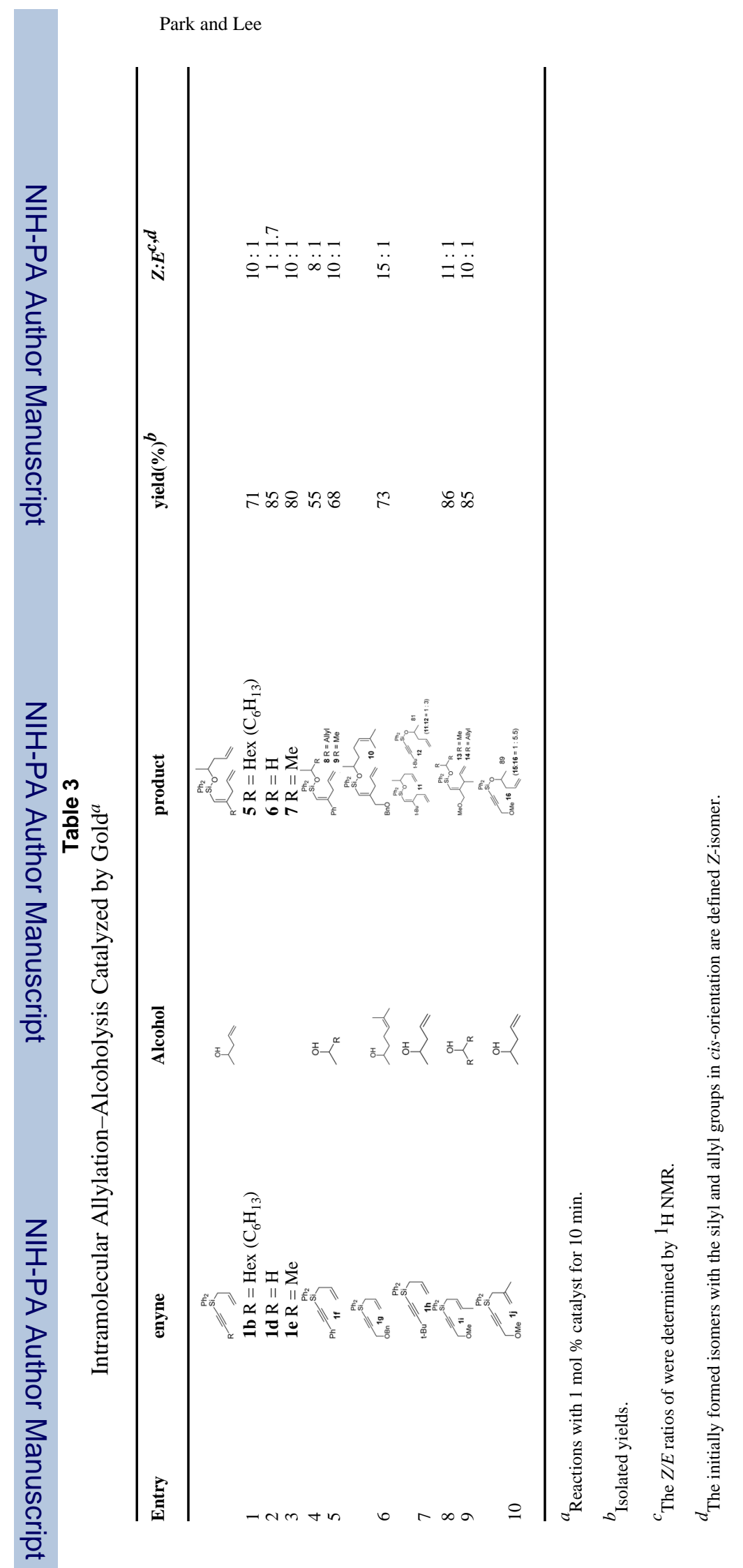

J Am Chem Soc. Author manuscript; available in PMC 2008 October 17. 